\title{
Effect of exposure to silica on human alveolar macrophages in supporting growth activity in type II epithelial cells
}

\author{
B Melloni, O Lesur, T Bouhadiba, A Cantin, M Martel, R Bégin
}

\begin{abstract}
Background - The proliferative response of type II cells is an important event following silica-induced lung injury. Alveolar macrophages, when activated by fibrogenic agents, secrete various biological mediators which affect cell growth.

Methods - Human alveolar macrophages from normal volunteers were incubated in serum-free medium or in the presence of increasing concentrations of silica. Alveolar macrophage conditioned media were diluted and added to type II cell cultures for proliferation studies. Purified type II pneumocytes were isolated from fetal rat lungs for bioassays. Growth factor activities were partially characterised by size exclusion chromatography. Each fractionated mitogenic peak was preincubated with monoclonal antibody against platelet derived growth factor (PDGF) or antisera against insulin-like growth factor 1 (IGF-1) or fibroblast derived growth factor (FGF) in order to study the nature of each activity.
\end{abstract}

Results - Conditioned media from alveolar macrophages exposed to silica induced an increase in type II cell DNA synthesis and cell number over that seen when type II cells were incubated with unstimulated alveolar macrophage supernatants. Size exclusion of alveolar macrophage supernatants exposed to silica showed four peaks of type II cell stimulating activity with apparent molecular weights of 38,22 , 16, and $8 \mathrm{kDa}$. Anti-PDGF antibody significantly reduced the activity of the first and second peaks, antiserum against IGF-1 partially reduced the activity of the first and fourth peaks, and antiserum against FGF reduced only the third peak of activity.

Conclusions-Human alveolar macrophages exposed to silica in vitro release mitogens for type II pneumocytes including PDGF-like, IGF-1-like, and FGF-like molecules. These agents are likely to be involved in the epithelial repair and type II cell hyperplasia observed in silicosis.

(Thorax 1996;51:781-786)
Keywords: alveolar macrophages, silicosis, type II cells.

Proliferation of type II pneumocytes is an early event following silica-induced lung injury in animal models. ${ }^{12}$ Type II cell hyperplasia has been reported after exposure to high levels of silica in humans and type II cells have been found in the bronchoalveolar lavage (BAL) fluid of acutely exposed workers. ${ }^{3}$ It is established that alveolar macrophages are important cells in the pathogenesis of silicosis by releasing mediators and messengers for other cell types and for the extracellular matrix. ${ }^{4-6}$ Alveolar macrophages are the main cell found in BAL fluid from patients with subclinical or simple silicosis. $^{67}$

We have studied the direct effect of low doses of silica on fetal rat type II cells in vitro, ${ }^{8}$ and have identified growth factor activity in BAL fluid from normal human lung that stimulates fetal rat type II cell growth in vitro. ${ }^{9}$ This mitogenic activity was clearly enhanced in BAL fluid from patients with early stages of silicosis. In addition, similar results were documented with BAL fluid from our experimental model of sheep silicosis. We have also found that conditioned media from alveolar macrophages of control sheep induced type II cell growth. ${ }^{10}$ Supernatants from in vitro or in vivo sheep alveolar macrophages exposed to silica significantly increased type II pneumocyte growth compared with those from nonexposed sheep alveolar macrophages. Partial characterisation of these mitogenic activities have recently been performed. ${ }^{11}$

It was hypothesised that human macrophages exposed in vitro to low doses of silica can be stimulated to release an increased mitogenic activity for type II cells. Factors involved in this macrophage-derived mitogenic activity are characterised in this study.

\section{Methods}

ALVEOLAR MACROPHAGE PREPARATIONS

Alveolar macrophages were obtained by bronchoalveolar lavage from 10 normal volunteers as described previously. ${ }^{7}$ The mean (SD) age of the subjects was 28 (3) years and all were non- 
smokers and had not been exposed to mineral dusts. The lavage fluid was filtered through surgical gauze and centrifuged at $400 \mathrm{~g}$ for 10 minutes. The cell pellet was suspended in Eagle's minimal essential medium (MEM; Gibco, Grand Island, New York, USA) supplemented with $10 \%$ fetal bovine serum (FBS) and antibiotics at a concentration of $2 \times 10^{6}$ cells. After one hour of adherence the cells were washed to remove non-adherent cells such as lymphocytes. Adherent cells were cultured in 24-well tissue culture plates (Falcon Inc, Lincoln Park, New Jersey, USA) in serum-free medium supplemented with $2 \mathrm{mM}$ glutamine, with or without mineral dusts (see below) and incubated for 24 hours at $37^{\circ} \mathrm{C}$ in $5 \% \mathrm{CO}_{2} /$ air. At the end of the culture period supernatants were removed, centrifuged $(500 \mathrm{~g}$ for 10 minutes), filtered through a $0.22 \mu \mathrm{m}$ filter (Millex-GS; Millipore Corp, Bedford, Massachusetts, USA) and stored at $-70^{\circ} \mathrm{C}$ until further use. The nature of the adherent cells was evaluated on a cytocentrifuge preparation stained with Wright-Giemsa. In all cases the resulting adherent cells were $\geqslant 92 \%$ alveolar macrophages with cell viability of $>95 \%$ as assessed by exclusion of trypan blue dye.

\section{EXPOSURE OF ALVEOLAR MACROPHAGES TO}

MINERAL DUSTS

Different concentrations of mineral dust particles were suspended in serum-free medium and added to macrophage cultures for 24 hours as reported previously. ${ }^{10}$ Silica (Minusil-5; Pennsylvania Glass Co, Pittsburgh, Pennsylvania, USA), titanium dioxide (Kronos Inc, Paris, France), or aluminum-treated quartz ${ }^{12}$ were heated for two hours at $200^{\circ} \mathrm{C}$ for sterilisation prior to use. All particles had a diameter of $<5 \mu \mathrm{m}$. Alveolar macrophage conditioned media were routinely checked for endotoxin contamination by the limulus amoebocyte assay (Sigma, St Louis, Missouri, USA). The alveolar macrophage supernatants were filtered through a $0.45 \mu \mathrm{m}$ filter and stored at $-20^{\circ} \mathrm{C}$ until required for cell proliferation assays.

EVALUATION OF SILICA DUST PARTICLES IN ALVEOLAR MACROPHAGES

The number of particles in alveolar macrophages was evaluated by polarised light microscopy. Quantification of the particles in the former evaluation was carried out by counting 500 cells for each sample with three independent determinations.

DUST CYTOTOXICITY ON ALVEOLAR

MACROPHAGES

Lactate dehydrogenase (LDH) release in culture medium was quantified to determine dust cytotoxicity on macrophages after incubation for 24 hours. ${ }^{10}$

ASSAY FOR TYPE II CELL GROWTH

Pneumocytes were isolated from fetal rat lungs as reported. ${ }^{8}$ These cells exhibited an immunocytochemical staining for cytokeratin 19, an intermediate filament specific to epithelial cells. Type II cells were used at passage 2 and were rendered quiescent by a 48 hour incubation in "breaking medium" (MEM) containing $2 \%$ serum (heat inactivated FBS). Conditioned media from alveolar macrophages exposed or not exposed to mineral dusts were added to the pneumocyte cultures. ${ }^{10}$ Given the log phase between DNA synthesis and cell division, cell growth was evaluated by the incorporation of tritiated thymidine at 24 hours and by counting the monolayers at 48 hours. $^{89}$

\section{PARTIAL CHARACTERISATION OF THE} MACROPHAGE-DERIVED MITOGENIC ACTIVITIES To produce sufficient amounts of growth promoting activity for partial purification, adherent cells from six normal individuals were incubated in serum-free medium supplemented with $50 \mu \mathrm{g} / \mathrm{ml}$ silica particles. This latter concentration induced the higher mitogenic activity on type II cells.

\section{Gel filtration}

Pooled alveolar macrophage supernatants from six healthy volunteers were lyophilised, concentrated 50-fold, and reconstituted in $1 \mathrm{ml}$ sterile phosphate buffered saline (PBS) as previously reported. ${ }^{11} \mathrm{Gel}$ filtration was performed on a G-75 SF column (Pharmacia Inc, Baie d'urfé, Québec, Canada) at a flow rate of 0.75 $\mathrm{ml} / \mathrm{min}$ and $2.5 \mathrm{ml}$ fractions were collected. The eluate was monitored by absorbance reading at $280 \mathrm{~nm}$. Fifty four fractions were diluted $1: 2$ in MEM supplemented by $2 \%$ serum and tested in type II cell DNA synthesis assays.

\section{Biophysical properties of macrophage-derived} mitogenic peaks

To study the properties of the alveolar macrophage derived growth activity, adjacent fractions with maximum activity for type II cells were pooled, lyophilised, and resuspended in medium as described above.

Acid treatment: Aliquots of mitogenic peak were dialysed against $1 \mathrm{M}$ acetic acid ( $\mathrm{pH} 2.5$, three changes, 24 hours), followed by dialysis against MEM.

Heat treatment: Aliquots of mitogenic peak were incubated at $100^{\circ} \mathrm{C}$ or $56^{\circ} \mathrm{C}$ for 30 minutes and then cooled at room temperature.

Role of reducing agent: Aliquots of mitogenic peak were incubated with $2 \mathrm{mM}$ dithiothreitol for 30 minutes at $37^{\circ} \mathrm{C}$ and dialysed against 1000 volumes of MEM (three changes, 24 hours).

Sensitivity to protease reduction: Aliquots of mitogenic peak were incubated with $1700 \mathrm{BAE}$ units of trypsin (type IX, 30 minutes, $37^{\circ} \mathrm{C}$ ) followed by incubation with twice the concentration of soybean trypsin inhibitor.

All treated aliquots were tested on type II cell $\left[{ }^{3} \mathrm{H}\right]$-thymidine incorporation and compared with an untreated aliquot prepared by the same process. All treated aliquots and controls were filtered prior to assay on type II cell cultures.

\section{Blocking antibodies}

Preincubation of $50 \mathrm{ng} / \mathrm{ml}$ human recombinant platelet-derived growth factor antibody (PDGF) with $50 \mu \mathrm{g} / \mathrm{ml}$ anti-PDGF IgG (Anti- 


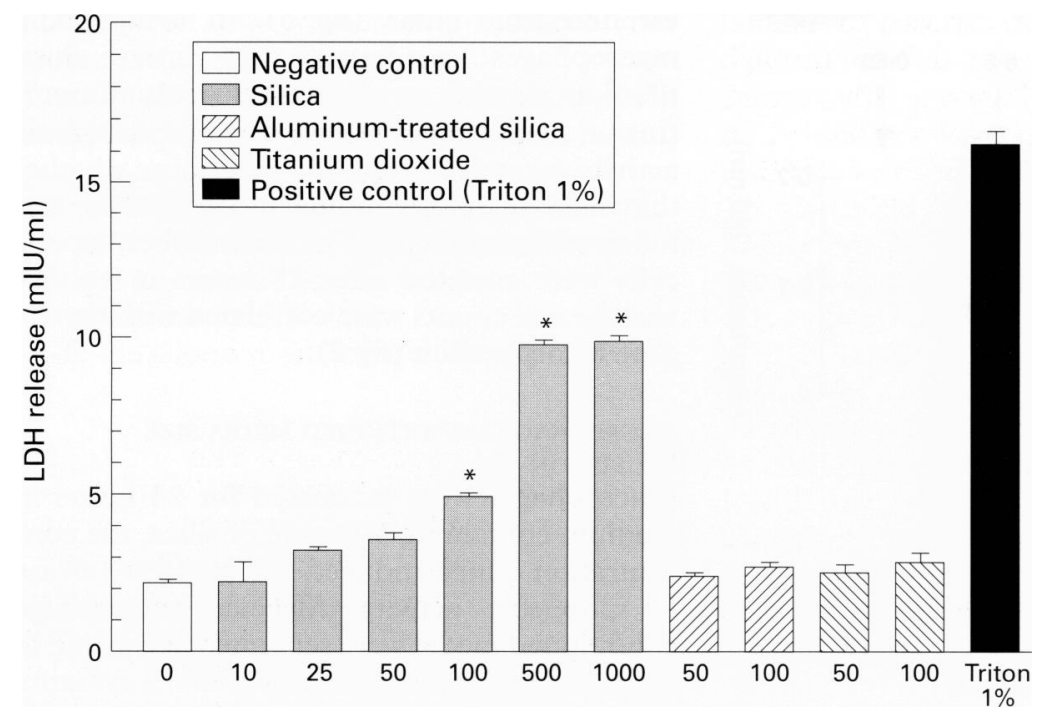

Figure 1 Release of lactate dehydrogenase by human alveolar macrophages exposed in vitro for 24 hours to silica, aluminum-treated silica, and titanium dioxide. $* p<0.05$ compared with control value. antibody or antiserum is specific for the corresponding cytokine.

\section{STATISTICAL ANALYSIS}

Data are expressed as mean (SE). Statistical significance $(p<0.05)$ was determined by analysis of variance (ANOVA) and a Student's $t$ test for comparison with control data.

\section{Results}

EFFECTS OF IN VITRO SILICA DUST EXPOSURE ON ALVEOLAR MACROPHAGES

Increasing concentrations of silica induced a higher release of $\mathrm{LDH}$ than under control conditions (fig 1); low doses of silica did not provoke a significant release of LDH. Treatment with titanium dioxide or aluminumtreated silica did not increase $\mathrm{LDH}$ release.

\section{EVALUATION OF SILICA PARTICLES IN ALVEOLAR} MACROPHAGES

Dust particles were rarely found in alveolar macrophages of control patients (2 (1)\% of total cells). A linear relationship between dust concentration and the percentage of adherent macrophages containing silica particles was found when silica was incubated with alveolar macrophages for 24 hours (8 (2)\% at $25 \mu \mathrm{g} / \mathrm{ml}$, $14(4) \%$ at $50 \mu \mathrm{g} / \mathrm{ml}, 22$ (5) $\%$ at $100 \mu \mathrm{g} / \mathrm{ml}$ ).

EFFECT OF MACROPHAGE SUPERNATANTS ON TYPE II CELL GROWTH

The effects of macrophage conditioned media were tested for their ability to induce the growth of fetal rat type II cells in vitro. Condifrom bovine pituitary extracts (IGF-1 and FGF, Collaborative Research Inc) were produced by immunisation of New Zealand white rabbits with IGF-1 emulsified in Freund's adjuvant. Rabbit antiserum to IGF-1 completely blocked the activity of $1 \mu \mathrm{g} / \mathrm{ml} \mathrm{IGF-1} \mathrm{on}$ type II cell DNA synthesis at a dilution of 1:500, and rabbit antiserum to FGF at a dilution of 1:2000 completely blocked the effect of $500 \mathrm{ng} / \mathrm{ml} \mathrm{FGF}$ on type II cell DNA synthesis. We have previously shown ${ }^{11}$ that each blocking

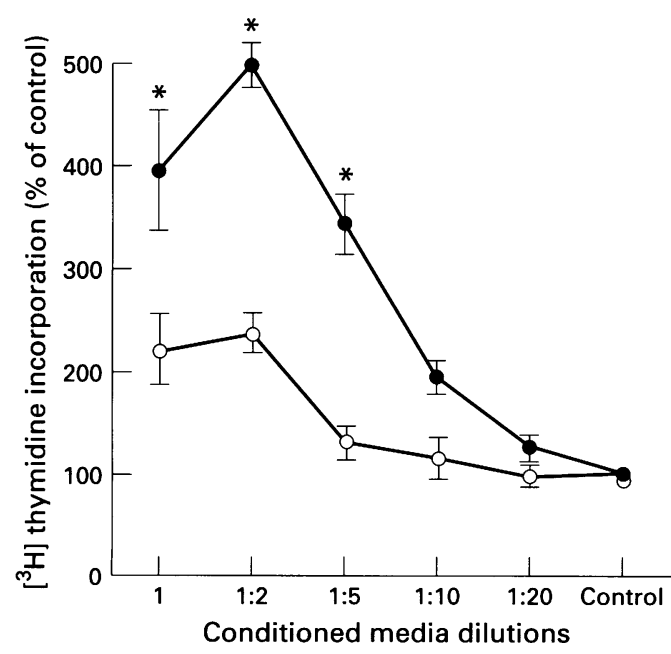

Figure 2 Comparison of the effect of supernatants from unstimulated macrophages (O) and macrophages exposed to silica in vitro (O) on incorporation of [ $\left.{ }^{3} \mathrm{H}\right]$-thymidine into type II cells. $* p<0.05$ versus unstimulated macrophage supernatants. Correlations between thymidine incorporation and cellular proliferation assessed by cell counting were significant at silica concentrations from 10 to $50 \mu \mathrm{g} / \mathrm{ml}\left(10 \mu \mathrm{g} / \mathrm{ml}: \mathrm{r}^{2}=0.14,25 \mu \mathrm{g} / \mathrm{ml}: \mathrm{r}^{2}=0.54,50\right.$ $\left.\mu g / m l: r^{2}=0.28, p<0.05\right)$.
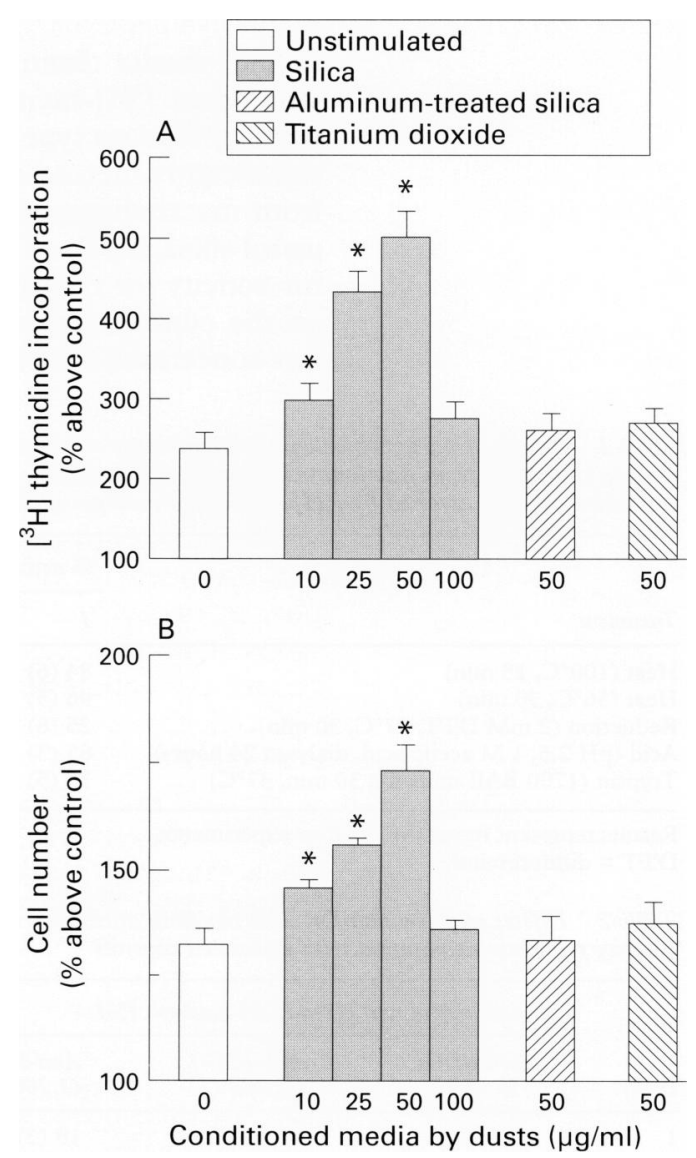

Figure 3 Effects of supernatants from dust-exposed (B) numbers of type II cells. *p $<0.05$ versus unstimulated macrophage supernatants. macrophages on (A) DNA synthesis of type II cells and 


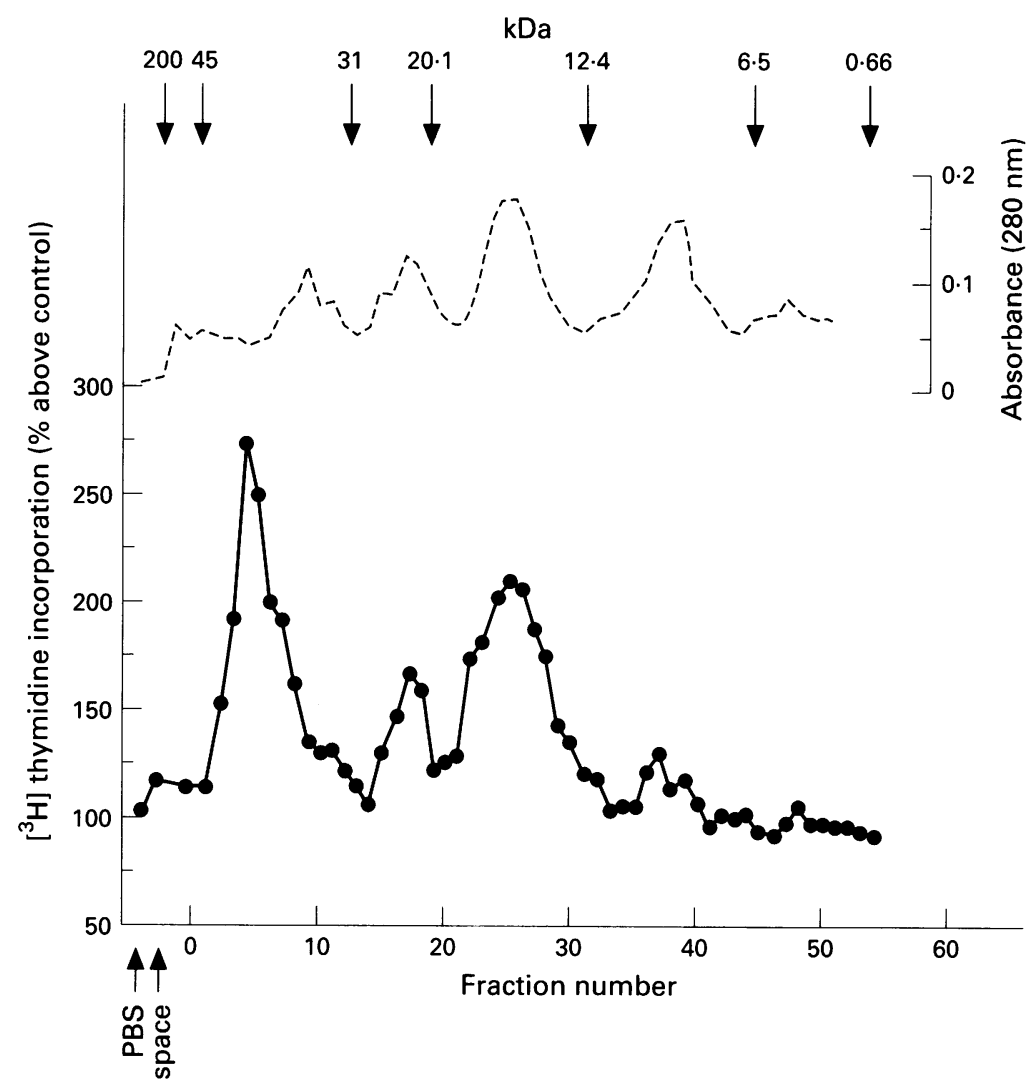

Figure 4 Size exclusion chromatography on Sephadex G-75 gel filtration. One ml of conditioned media from macrophages exposed to silica (concentrated 50 times) was eluted and each resulting fraction was tested for type II cell [ $\left.{ }^{3} \mathrm{H}\right]$-thymidine incorporation ()).

The absorbance of fraction protein content was monitored at $280 \mathrm{~nm}(\cdots)$. Molecular weight standards (arrows), starting with the highest, are blue dextran, ovalbumin, deoxyribonuclease-1, soybean trypsin inhibitor, cytochrome $C$, aprotinin, and oxidised glutathione. Data from one representative experiment out of four are shown.

tioned media from adherent macrophages stimulated $\left[{ }^{3} \mathrm{H}\right]$-thymidine incorporation into primary fetal rat type II cells and this effect was significantly increased with conditioned media from macrophages incubated in vitro with 50 $\mu \mathrm{g} / \mathrm{ml}$ silica (fig 2 ). The amount of growth factor activity for type II cells released depended on the concentration of silica dust used, with low concentrations of silica inducing the great-

Table 1 Effects of various biochemical treatments on the percentage activity remaining in the peaks isolated from fractionated macrophage conditioned media compared with untreated controls assessed by $\left[^{3} \mathrm{H}\right]$-thymidine incorporation in type II cells

\begin{tabular}{lllll}
\hline & \multicolumn{5}{l}{$\%$ activity remaining in peak } \\
\cline { 2 - 5 } Treatment & 1 & 2 & 3 & 4 \\
\hline Heat $\left(100^{\circ} \mathrm{C}, 15 \mathrm{~min}\right)$ & $84(6)$ & $88(6)$ & $61(4)$ & $64(9)$ \\
Heat $\left(56^{\circ} \mathrm{C}, 30 \mathrm{~min}\right)$ & $96(5)$ & $92(3)$ & $79(5)$ & $88(7)$ \\
Reduction $\left(2 \mathrm{mM}\right.$ DTT, $\left.37^{\circ} \mathrm{C}, 30 \mathrm{~min}\right)$ & $25(8)$ & $72(6)$ & $63(4)$ & $75(6)$ \\
Acid $(\mathrm{pH} 2.5,1 \mathrm{M}$ acetic acid, dialysed 24 hours $)$ & $85(3)$ & $82(5)$ & $73(5)$ & $48(8)$ \\
Trypsin $\left(1700 \mathrm{BAE}\right.$ units $\left./ \mathrm{ml}, 30 \mathrm{~min}, 37^{\circ} \mathrm{C}\right)$ & $39(5)$ & $44(7)$ & $33(4)$ & $32(5)$ \\
\hline
\end{tabular}

Results represent mean (SE) of four experiments.

DTT $=$ dithiothreitol.

Table 2 Effects of preincubation with blocking antibodies on percentage of mitogenic activity remaining compared with untreated controls

\begin{tabular}{lllll}
\hline \multicolumn{5}{c}{ Inhibition of type II cell DNA synthesis (\%) } \\
\cline { 2 - 5 } Peaks & $\begin{array}{l}\text { Anti-PDGF } \\
(50 \mu g / m l)\end{array}$ & $\begin{array}{l}\text { Anti-IGF-1 } \\
(1: 500)\end{array}$ & $\begin{array}{l}\text { Anti-FGF } \\
(1: 2000)\end{array}$ & $\begin{array}{l}\text { Anti-PDGF + } \\
\text { anti-IGF-1 }\end{array}$ \\
\hline 1 & $40(5)$ & $37(4)$ & $19(3)$ & $34(10)$ \\
2 & $27(3)$ & $26(9)$ & $14(5)$ & $46(5)$ \\
3 & $6(2)$ & $15(3)$ & $50(6)$ & $3(2)$ \\
4 & $16(4)$ & $35(4)$ & $12(3)$ & $30(7)$ \\
\hline
\end{tabular}

Results represent mean (SE) of four experiments. est mitogenic effect (fig 3). In comparison, macrophages incubated with inert dust/ titanium dioxide or modified dust/aluminiumtreated silica did not release a similar mitogenic activity for type II cells. To determine whether the increase in thymidine incorporation was followed by an increase in cell number, type II cells were counted after 48 hours in culture and the cell counts were correlated with thymidine incorporation (fig 2).

\section{MACROPHAGE CONDITIONED MEDIA SIZE EXCLUSION}

Macrophages were incubated for 24 hours in medium containing $50 \mu \mathrm{g} / \mathrm{ml}$ of silica, the concentration which induced the greatest release of mitogenic activity. Alveolar macrophage conditioned media were separated according to their molecular weights with a G-75 column. Type II cell growth promoting activity (for example, $\left[{ }^{3} \mathrm{H}\right]$-thymidine incorporation) was detected in four peaks (fig 4). The highest mitogenic peaks eluted with apparent molecular weights of $38 \mathrm{kDa}$ (first peak) and $16 \mathrm{kDa}$ (third peak). In addition, two smaller peaks were detected with apparent molecular weights of $22 \mathrm{kDa}$ (second peak) and $8 \mathrm{kDa}$ (fourth peak).

PHYSICAL PROPERTIES OF MITOGENIC ACTIVITIES Each peak was subjected to various treatments to determine the biochemical properties of macrophage growth promoting activities for type II cells (table 1). Heating the first and second peaks to $100^{\circ} \mathrm{C}$ for 10 minutes or to $56^{\circ} \mathrm{C}$ for 30 minutes resulted in only a slight reduction in mitogenic activity compared with the third and fourth peaks. On the other hand, the first and second peaks were more resistant to acid treatment than the third and fourth peaks of activity. The reducing agent dithiothreitol significantly altered the activity of the first peak. Treatment of each peak with trypsin resulted in a considerable loss of growth promoting activity.

NEUTRALISING ANTIBODIES IN MITOGENIC PEAKS Antibody against PDGF and antisera against IGF-1 and FGF were used to block the mitogenic activity of each peak fractionated from silica-exposed macrophage supernatants (table 2). A significant part of the mitogenic activity of the first and second peaks was inhibited by anti-PDGF IgG ( $40 \%$ for the first peak and $27 \%$ for the second peak). Anti-IGF-1 antiserum substantially reduced the activity of the first $(37 \%)$, second $(26 \%)$, and fourth (35\%) peaks of activity; anti-FGF antiserum affected the mitogenic activity of all peaks, but only that of the third peak $(50 \%)$ to a significant extent. Several combinations of anti-PDGF IgG and antisera against IGF-1 or FGF were tested and a synergistic neutralising effect on the second peak ( $46 \%$ ) was shown by the combination of anti-PDGF with antiIGF-1. On the other hand, the addition of either anti-PDGF antibody or antisera against IGF-1 or FGF alone to unfractionated conditioned media had no effect on type II cell DNA synthesis (data not shown). 


\section{Discussion}

Many recent studies have focused on the ability of inorganic particles to induce secretion of fibroblast mitogenic activities by macrophages in vitro. ${ }^{1314}$ Macrophages isolated from patients exposed to silica dust released in vitro an alveolar macrophage-derived progression growth factor ${ }^{15}$ which is involved in fibroblast regulation and has been shown to be an IGF-1 molecule with a molecular weight of 18-25 $\mathrm{kDa} .{ }^{16}$ Type II cell hyperplasia in animal models appears to be an early event following type I epithelial damage ${ }^{2}$ and this also appears to be a feature of human silicosis. ${ }^{3}$ In this study the nature of the mitogenic activities for type II cells released by human alveolar macrophages incubated in vitro with low doses of silica was investigated.

We have previously explained the choice of fetal rat type II cells for bioassays. ${ }^{8}$ Earlier studies have shown that fetal rat type II cells were differentiated at 19 days and expressed different markers of alveolar epithelial cells. ${ }^{17}$ Most importantly, fetal type II cells are able to divide in cultures and the cell numbers are strictly correlated with DNA synthesis in our model. Of the well known mitogenic factors, PDGF, FGF, and IGF-1 stimulate fetal type II cell growth in vitro, ${ }^{911}$ and these are released spontaneously by activated alveolar macrophages. ${ }^{18}$

Our results indicate that supernatants from human alveolar macrophages exposed to silica in vitro induced a significantly greater increase in fetal type II cell growth than that seen with supernatants from unstimulated adherent macrophages. This effect is specific for silica particles and was not observed with inert dust/ titanium dioxide or modified dust/aluminumtreated silica. Importantly, low doses of silica induced the highest growth factor activity. This observation confirms the results previously reported with sheep alveolar macrophages exposed in vitro or in vivo to silica. ${ }^{11}$ Activation of macrophages by silica could stimulate their production of macrophage derived growth factor for type II cells. The percentage of macrophages in the BAL fluid that contained particles of silica dust was $52 \%$ in the subjects exposed to silica and only $6 \%$ in control subjects. ${ }^{19}$ A non-cytotoxic concentration of 50 $\mu \mathrm{g} / \mathrm{ml}$ of silica was used for partial characterisation in our experiments. At this concentration, only $14 \%$ of the cells contained cytoplasmic mineral particles.

Pneumoconioses are characterised by an alveolitis rich in alveolar macrophages. ${ }^{367}$ The release of soluble mediators from alveolar macrophages in patients with silicosis has been involved in the pathogenesis of inflammation and fibrosis. ${ }^{4}{ }^{5}$ It is well established that the interaction between macrophages and silica is an early event in the inflammatory response to mineral dust. In addition, alveolar type II cell proliferation is an important process which occurs after most types of lung injury including exposure to silica dust. The mechanisms that regulate alveolar type II cell proliferation in lung injury are poorly understood. We have documented a proliferative activity for fetal type II cells in BAL fluid from healthy volunteers in our previous studies ${ }^{9}$ and have shown that this activity was significantly enhanced in BAL fluid from patients exposed to silica which suggests that the mitogenic activity of epithelial cells in the BAL fluid could at least partly be released by macrophages. These findings are consistent with previous reports which have shown that conditioned media from rat or human alveolar macrophages stimulated adult rat type II cell DNA synthesis. ${ }^{20}$ The BAL fluid from normal rats induces DNA synthesis in adult rat type II cells. $^{21} \mathrm{~A}$ recent study has characterised the nature of the alveolitis in the lower respiratory tract of patients with pneumoconiosis. Alveolar macrophages from subjects exposed to asbestos or silica spontaneously release mitogenic activity for lung fibroblasts and fibronectin, an important component of the extracellular matrix. ${ }^{15}$ In a recent study of patients with coal workers'pneumoconiosis the production of PDGF, IGF-1, and transforming growth factor $\beta$ (TGF- $\beta$ ) was demonstrated in alveolar macrophage supernatants and the role of PDGF and IGF-1 was associated with fibroblast growth. ${ }^{22}$

Partial characterisation of these mitogenic activities for type II cells was performed and size exclusion chromatography showed four distinct peaks of growth promoting activity in alveolar macrophage supernatants exposed to silica. Most of the four distinct peaks of activity were lost with trypsin treatment, suggesting a proteinic nature. The first and second peaks of apparent molecular weights of $38 \mathrm{kDa}$ and 22 $\mathrm{kDa}$, respectively, were resistant to acid and heat and were also partially inhibited by the anti-PDGF IgG. These results suggest that these factors could be PDGF-like molecules or that they are closely related to IGF-1 molecules. IGF-1 is an $18 \mathrm{kDa}$ mediator implicated in mineral dust diseases and shares similarities with PDGF or IGF-1 molecules. ${ }^{6} 1518$ Antiserum against IGF-1 partially inhibited the activity of the first and second peaks, and the combination of anti-PDGF with antiIGF-1 was synergistic in blocking the activity of the second peak. The third peak of type II cell mitogenic activity has an apparent molecular weight of $16 \mathrm{kDa}$ and was sensitive to acid and heat and was considerably reduced by preincubation with antiserum against FGF. This activity could be an FGF-like molecule or a cleavage product of another peptide. The fourth activity peak has a small molecular weight of $8 \mathrm{kDa}$ which was also acid-sensitive and partially reduced by preincubation with antiserum against IGF-1. In this area the 7 $\mathrm{kDa}$ bloodstream form of IGF-1 could be implicated, ${ }^{18-23}$ or other peptides which are known to induce fetal type II cell growth could be suspected such as EGF and TGF- $\alpha .^{924}$

The nature of the mitogenic activities for epithelial cells is not completely characterised by these conventional methods because of difficulties with the induction of secretion of growth factors by alveolar macrophages in the artificial environment of cell culture and the differences between species. Furthermore, the 
activities of combinations of cytokines are complex and cannot be predicted from the activity of each individual cytokine. ${ }^{18}$

PDGF has been identified as a cationic protein with an apparent molecular weight of $28-35 \mathrm{kDa}$. It is known to behave as two distinct peptide chains (chains A and B) that are synthesised in high molecular weight precursors and are processed before secretion. On the other hand, PDGF-like activities are detected in vitro in conditioned media from various cells such as macrophages. There are many differences in the molecular weights of PDGF isoforms. Monomeric forms outline the existence of a growing family of related cytokines, the so called PDGFs. The partial purification of PDGF-like activity can be attributed to the presence of different PDGF isoforms. The characterisation may also be confused by the presence of circulating binding proteins which can modify the apparent molecular weight of these factors. ${ }^{23}{ }^{25}$ Hence, purification of IGFs reveals a larger molecular weight in relation to the combination of IGFs to their binding proteins. IGF-1 is a peptide of $7.6 \mathrm{kDa}$ in serum and $18 \mathrm{kDa}$ in macrophage supernatants, but the highest molecular weight of $38 \mathrm{kDa}$ corresponds with the IGF binding protein. ${ }^{25}$ The existence of IGF binding proteins in conditioned media could explain our results. Secretion of growth factors in vivo may be driven by mediators secreted by other cells such as lymphocytes which participate in the inflammatory response to silica, ${ }^{26}$ but these mediators may not be present in in vitro experiments with macrophages in BAL fluid. Nevertheless, the results of our study are in agreement with previous data that have shown that alveolar macrophages exposed to mineral dust release cytokine-like activity. ${ }^{13-15} 22$

In conclusion, this study has confirmed that mitogenic factors for type II cell growth in vitro are produced by macrophages exposed to silica. Macrophages activated by silica phagocytosis could play a key regulatory role in alveolar epithelial repair. Of the known growth factors, PDGF-like, IGF-1-like, and FGF-like molecules could be implicated in the regulation of type II cell growth after lung injury. Further investigations are required to analyse this non-specific response to silica at a molecular level.

\section{This study was supported by MRC Canada.}

1 Rennard SE, Bitterman PB, Crystal RG. Response of the lower respiratory tract to injury. Mechanisms of repair of the parenchymal cells of the alveolar wall. Chest 1984; 6:735-9.
2 Miller BE, Dethloff LA, Hook GER. Progression of type II cell hypertrophy and hyperplasia during silica-induced cell hypertrophy and hyperplasia during silica-indu

3 Schuyler MR, Gaumer HR, Stankus RP, Kaimal J, Hoffmann E, Salvaggio JE. Bronchoalveolar lavage in silicosis. Evidence of type II cell hyperplasia. Lung 1980 157:95-102.

4 Davis GS. Pathogenesis of silicosis: current concepts and hypotheses. Lung 1986;164:139-54

5 Scheule RK, Holian A. Immunologic aspects of pneumoconiosis. Exp Lung Res 1991;17:661-85.

6 Rom WN. Relationship of inflammatory cell cytokines to disease severity in individuals with occupational inorganic dust exposure. Am ₹ Ind Med 1991;19:15-27.

7 Bégin R, Cantin A, Boileau R, Bisson G. Spectrum of alveolitis in quartz-exposed human subjects. Chest 1987 92:1061-7.

8 Lesur O, Cantin A, Tanswell AK, Melloni B, Beaulieu JF, Bégin R. Silica exposure induces cytotoxicity and proliferative activity of type II pneumocytes. Exp Lung Res 1992;18:173-90.

9 Lesur O, Melloni B, Cantin A, Bégin R. Silica-exposed lung fluids have a proliferative activity for type II epithelial cells. A study on human and sheep alveolar fluids. Exp Lung Res A study on human

10 Melloni B, Lesur O, Cantin A, Bégin R. Silica-exposed macrophages release a growth-promoting activity for type II pneumocytes. F Leukoc Biol 1993;53:327-35.

11 Melloni B, Lesur O, Bouhadiba T, Cantin A, R Bégin. Partial characterization of the proliferative activity for fetal lung epithelial cells produced by silica-exposed alveoalar macrophages. F Leukoc Biol 1993;55:574-80.

12 Bégin R, Massé S, Rola-Plesczynski M, Martel M, Desmarais $\mathrm{Y}$, Geoffroy $\mathrm{M}$, et al. Aluminum lactate treatment alters the lung's biological activity of quartz. Exp Lung Res 1986;10:385-99.

13 Bauman MD, Jetten AM, Bonner JC, Kumar RK, Bennet RA, Brody AR. Secretion of a platelet-derived growth factor by rat alveolar macrophages exposed to particulates in vitro. Eur f Cell Biol 1990;51:327-34.

14 Kumar RK, O Grady R, Li W, Velan GM. Mitogenic activity for fibroblasts induced by silica and titanium dioxide particles in vitro and in vivo. Int $\mathcal{f}$ Exp Pathol 1992;73:573 83.

15 Rom WN, Bitterman PB, Rennard SI, Cantin A, Crystal RG. Characterization of the lower respiratory tract inflamRG. Characterization of the lower respiratory tract inflam-
mation of nonsmoking individuals with interstitial lung mation of nonsmoking individuals with interstitial lung
disease associated with chronic inhalation of inorganic disease associated with chronic inhalation
dusts. Am Rev Respir Dis 1987;136:1429-34.

16 Rom WN, Basset P, Fells GA, Nukiwa T, Trapnell BC, Crystal RG. Alveolar macrophages release an insulin-like growth factor 1-type molecule. f Clin Invest 1988; 82:1685-93.

17 Post M, Smith BT. Histochemical and immunocytochemical identification of alveolar type II epithelial cells isolated from fetal rat lung. Am Rev Respir Dis 1988;137:525-30.

18 Kelley J. Cytokines of the lung: state of the art. Am Rev Respir Dis 1990;141:765-88.

19 Takemura T, Rom WN, Ferrans VJ, Crystal RG. Morphologic characterization of alveolar macrophages from subjects with occupational exposure to inorganic particles. Am Rev Respir Dis 1989;140:1674-85.

20 Leslie CC, McCormick-Shannon K, Robinson PC, Mason RJ. Stimulation of DNA synthesis in rat alveolar type II cells. Am Rev Respir Dis 1985;132:1246-52.

21 Leslie CC, McCormick-Shannon K, Mason RJ. Bronchoalveolar lavage fluid from normal rats stimulates DNA synveolar lavage fluid from normal rats stimulates DNA syn-
thesis in rat alveolar type II cells. Am Rev Respir Dis 1989; 139:360-6.

22 Vanhee D, Gosset P, Wallaert B, Voisin C, Tonnel AB. Mechanisms of fibrosis in coal workers' pneumoconiosis. Am $\mathcal{F}$ Respir Crit Care Med 1994;150:1049-55.

23 King RJ, Jones MB, Minoo P. Regulation of lung cell proliferation by polypeptide growth factors. Am F Physiol 1989; 257:L23-38.

24 Stiles AD, Smith BT, Post M. Reciprocal autocrine and paracrine regulation of growth of mesenchymal and alveoparacrine regulation of growth of mesenchymal and alveo198 epithelial cells

25 Sara VR, Hall K. Insulin-like growth factors and their binding proteins. Physiol Rev 1992;70:591-614.

$26 \mathrm{Li} \mathrm{W,} \mathrm{Kumar} \mathrm{RK,} \mathrm{O'Grady} \mathrm{R,} \mathrm{Velan} \mathrm{GM.} \mathrm{Role} \mathrm{of}$ lymphocytes in silicosis: regulation of secretion of macrophage-derived mitogenic activity for fibroblasts. Int f Exp Pathol 1992;73:793-800. 